\title{
A rare cause of haematochezia: pyogenic granuloma in colon
}

Hong Kong Med J 2014;20:168.e1-2

KL Lui ${ }^{*, 1}, \mathrm{KS} \mathrm{Ng}^{2}$, Michael KK Li ${ }^{1}$

DOI: $10.12809 / \mathrm{hkmj} 133844$

A 74-year-old man presented with haematochezia (passage of fresh blood per rectum) for 1 day, and a history of diabetic nephropathy and fatty liver going back 10 years. The haemoglobin level dropped from $140 \mathrm{~g} / \mathrm{L}$ to $90 \mathrm{~g} / \mathrm{L}$ over 6 months. Colonoscopy revealed a 'malignant looking' ascending colon polyp with a whitish coating and easy contact bleeding (Fig 1). Polypectomy was performed but complicated with profuse bleeding which was controlled with a haemoclip. The histology confirmed the lesion to be pyogenic granuloma (PG) with a lobular arrangement of capillaries in an oedematous stroma (Fig 2) and endothelial cells staining positive for CD31, CD34

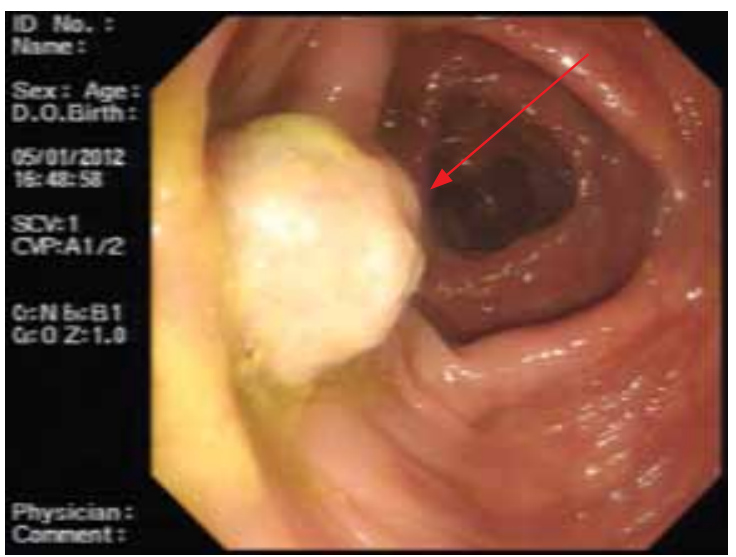

FIG I. The endoscopic appearance of pyogenic granuloma with a whitish coating on its surface (red arrow)

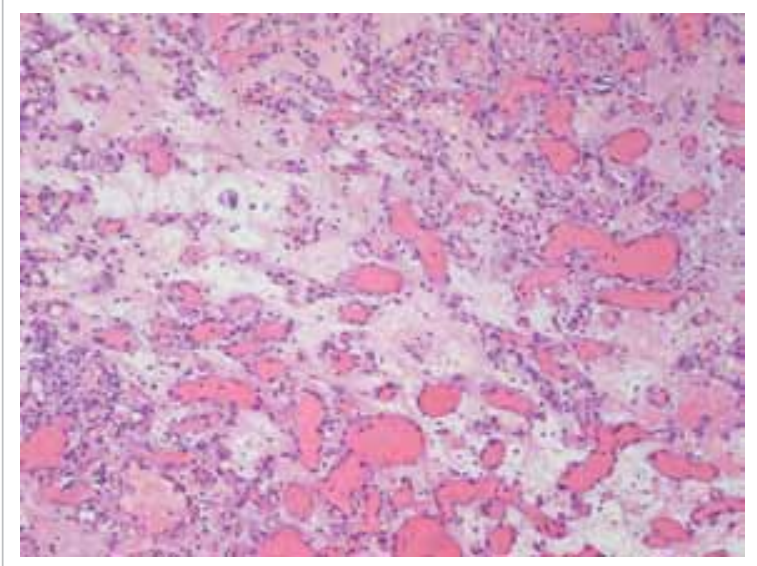

FIG 2. High-power view of the tumour

The tumour is composed of lobular arrangement of capillaries in an oedematous stroma (H\&E stain, $\times 100)$
(Fig 3), and tissue factor VIII.

This form of granuloma is a very rare cause of haematochezia. Usually, PG occurs on the skin after repeated trauma; only a few colonic cases have been reported. ${ }^{1,2}$ Macroscopically, it is usually described as a red, polypoid mass of apparent granulation tissue and surface ulceration or with a whitish coating that bleeds easily upon contact. Microscopically it is best described as a capillary haemangioma arranged in a lobular pattern, with clusters of small capillaries lined by a single layer of bland endothelial cells. The stroma is often oedematous and filled with a dense neutrophilic infiltrate. The most useful markers are the presence of elements that stain for tissue factors VIII and CD31, and CD34, on endothelial cells lining capillary loops. The exact cause of PG remains unknown, but trauma, post-irritation, post-surgery, viral causes (eg human herpesvirus-8) have all been
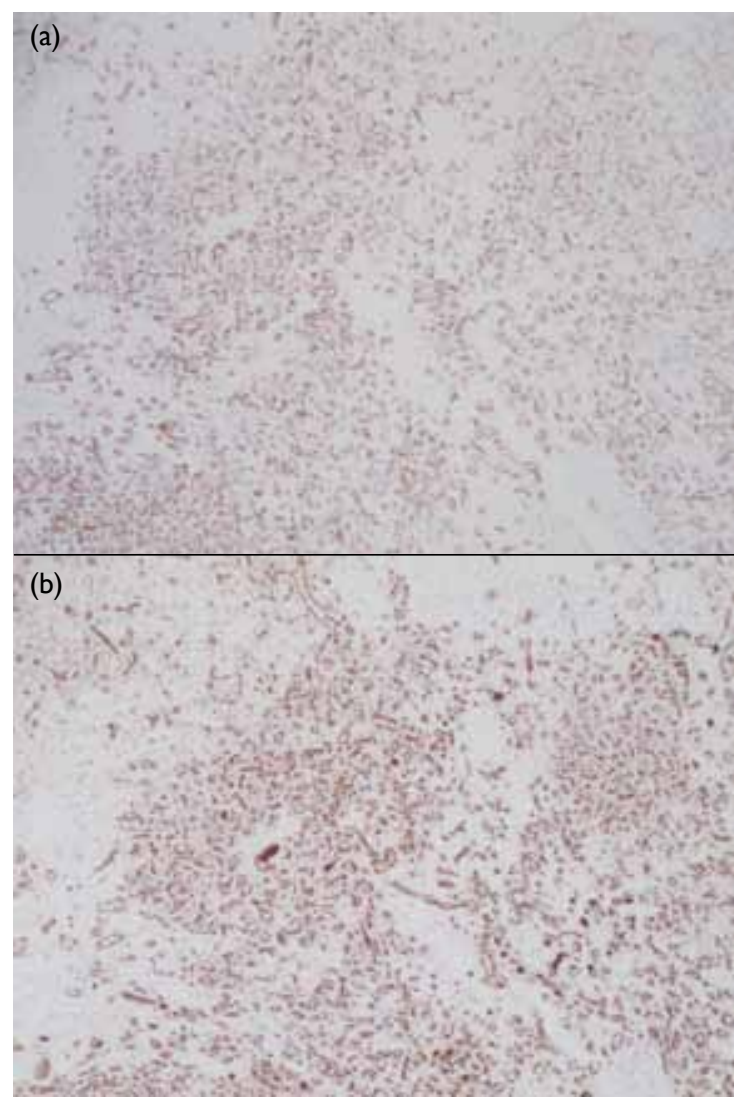

FIG 3. Immunohistochemical staining showing (a) CD3Ipositive endothelial cells and (b) CD34-positive endothelial cells 
postulated but never proven. ${ }^{1,2}$ Colonic PGs usually present with haematochezia with or without anaemia and sometimes the bleeding can be massive. The lesion is usually completely excised by endoscopic polypectomy. However, since it bleeds extremely easily, post-polypectomy haemostasis is usually necessary and sometimes angiographic embolisation is performed. ${ }^{3}$ Therefore, early recognition of the endoscopic appearance of PGs is essential..

${ }^{1} \mathrm{KL} \mathrm{Lui}{ }^{*}$, MRCP(UK), FHKCP

${ }^{2} \mathrm{KS} \mathrm{Ng}, \mathrm{MB}, \mathrm{ChB}$

${ }^{1}$ MKK Li, FRCP, FHKAM (Medicine)

${ }^{1}$ Division of Gastroenterology and Hepatology, Department of Medicine and Geriatrics
${ }^{2}$ Department of Pathology

Tuen Mun Hospital, Tuen Mun, Hong Kong

* Corresponding author: klluitc@yahoo.com.hk

\section{References}

1. Iwasaka C, Yazu T, Suehiro A, et al. A case of pyogenic granuloma in the sigmoid colon [in Japanese]. Nippon Shokakibyo Gakkai Zasshi 1995;92:885-8.

2. Nakaya $T$, Tokunaga $T$, Aono $S$, et al. Pyogenic granuloma of the descending colon. Endoscopy 2007;39(Suppl 1):E259-60.

3. Kusakabe A, Kato H, Hayashi K, et al. Pyogenic granuloma of the stomach successfully treated by endoscopic resection after transarterial embolization of the feeding artery. J Gastroenterol 2005;40:530-5. 